\title{
Formação de jovens trabalhadores associados na produção da vida: questões para debate ${ }^{1}$
}

\author{
Lia Tiriba ${ }^{\mathrm{I}}$ e Maria Clara Bueno Fischer ${ }^{\mathrm{II}}$ \\ ${ }^{\mathrm{I}}$ Universidade Federal Fluminense \\ II Universidade Federal do Rio Grande do Sul
}

\begin{abstract}
Em formato de ensaio, o texto revela que, para enfrentar a crise estrutural do emprego e a precarização do trabalho, alguns jovens têm se organizado em torno do movimento por uma economia popular solidária. Com o propósito de refletir sobre a formação de jovens trabalhadores que se associam para garantir a reprodução ampliada da vida, são articulados alguns conceitos como juventude, associativismo, produção associada, cultura do trabalho e autogestão. A partir de informações extraídas do grupo de discussão E-solidária, são feitas referências às organizações econômicas associativas, criadas e dirigidas por jovens, cuja racionalidade econômica, ao contrário do "empreendedorismo", se diferencia da lógica da economia capitalista. Enfatiza-se que problematizar o trabalho significa problematizar as atuais e as futuras relações entre escola e sociedade; ressignificar o trabalho dos jovens é ressignificar o sentido da escola como instituição social e, ao mesmo tempo, a maneira com que ela é percebida, hoje, pelos próprios jovens, que estão experimentando trabalhar de forma associativa e autogestionária.
\end{abstract}

Palavras-chave: Juventude, Trabalho e educação, Cultura do trabalho, Economia popular solidária, Associativismo.

Formation of young workers associated to produce life: issues for debate

This essay reveals that to face the structural crisis of employment and the process of precariousation of work conditions, youths have participated in the movement for a solidary popular economy. In order to discuss about education for these young people that have associated themselves to guarantee an enlarged reproduction of life, we haveconsidered in an articulated way some concepts as follows: youth, associativity, associated production, culture of work and self-management. Along the article, references are made to associative economical organizations, established and driven by youths, whose economical rationality, unlike the so-called "empreendedorismo", differs from the logic of capitalist economy. It is emphasized that in order to problematize work one has to problematize the current and future relations between school and society; and, also, to re-signify work for youth is, simultaneously, resignifying the meaning of school as social institution as well as the way it is perceived by the very youths who are struggling to work in an associative and self-managed form.

Keywords: Youth, Work and education, Culture of work, Solidary popular economy, Associativity.

$\mathrm{T}$ ornou-se lugar comum dizer que o "futuro" do país e do planeta depende dos jovens de "hoje". À juventude atribui-se uma grande carga de responsabilidade! Em última instância, tem-se a esperança de que eles sejam melhores que as gerações anteriores; que possam realizar o que não se conseguiu e ou não se foi capaz de realizar. Deseja-se que os filhos sejam felizes, que possam estudar, ter um bom emprego... que possam "ser alguém na vida". Entre tantas coisas, deseja-se que a "cria" construa um mundo melhor. Mas, que mundo é esse? Onde esse mundo começa? Em que medida a inserção dos jovens, no trabalho associado, pode contribuir para a produção de um novo mundo, de nova cultura do trabalho? Junto e com a juventude, como se constrói - hoje - a realidade? Que futuro se aguarda?

$1 \mathrm{O}$ ensaio intitulado Jovens trabalhadores associados na produção da vida: entre o desemprego, a precarização do trabalho e a economia popular solidária (Tiriba \& Fischer, 2007) serviu de inspiração e base para este artigo. 
Juventude pode ser compreendida como aquela fase da vida de transição entre a heteronomia da infância e a autonomia do adulto. A duração e as características dessa fase variam muito, em função dos sujeitos concretos a quem se está referindo e, também, da perspectiva teórica adotada. A Organização das Nações Unidas (ONU) considera, como segmento juvenil, a população situada entre 15 e 24 anos; já a Secretaria Nacional da Juventude, criada no Brasil em 2005, considera jovens todos aqueles que se situam entre $15 \mathrm{e}$ 29 anos. É importante, no entanto, considerar a possibilidade de alteração desses limites, em função das diferenças entre as sociedades, as classes sociais e variáveis como etnia e gênero. Definir juventude, no singular, está cada vez mais difícil; por isso, toma assento a ideia de juventude, no plural: juventudes.

Estima-se que, atualmente, a juventude brasileira seja a quinta maior do mundo (Pochmann, 2006). Existem, no País, mais de 35 milhões de jovens, entre os quais 17 milhões estudam, e os outros não. Daqueles que estudam, $56 \%$ estão fora da série regular de ensino. Avalia-se que mais de 5 milhões de jovens, de 16 (idade mínima legal para inserção no mercado de trabalho) a 24 anos de idade, não trabalham, não estudam nem procuram trabalho (Pochmann, 2006). Os jovens somam 25\% da População Economicamente Ativa (PEA), o que corresponde a 4,6 milhões de indivíduos, de um total de 18,5 milhões, distribuídos em cinco grandes regiões metropolitanas e Distrito Federal. Dos 4,6 milhões, 3,2 milhões estão ocupados e 1,4 milhão desempregados. O número de jovens ocupados representa 20,7\% da PEA ocupada e $45,5 \%$ do número total de pessoas desempregadas, com mais de 16 anos.

Esses dados são indicadores expressivos de que a população jovem, em idade de trabalhar, está mais vulnerável ao desemprego. Além disso, constata-se que os de família de menor renda encontram mais dificuldade para se inserir no mercado do trabalho assalariado. Algumas características se destacam, em relação àqueles que estão ocupados: em geral, são do sexo masculino, com Ensino Médio completo, extensa jornada de trabalho, dificuldade de conciliar trabalho e estudo. Trata-se de assalariados, com carteira de trabalho assinada e com rendimento de um a dois salários mínimos. Os ocupados, oriundos de famílias com rendimento mais elevado, embora tenham um perfil mais elevado, possuem extensas jornadas de trabalho (Dieese, 2006). São interessantes, também, dados relativos aos jovens de famílias pobres. Nesse caso, o nível médio de escolarização é o Ensino Fundamental incompleto e, nesse estágio de vida, a maioria apenas trabalha, recebendo menos que um salário mínimo. Poder-se-ia concluir, então, que o nível de escolarização determina a possibilidade e a qualidade da inserção dos jovens no mercado de trabalho. Apesar disso, além de as pesquisas indicarem que não há uma relação direta entre formação - geral ou profissional - e inserção e permanência no mercado de trabalho, é preciso reconhecer que a injusta distribuição de renda é um dos fatores fundantes das dificuldades de o jovem frequentar a escola.

A transição para uma condição de autonomia caracteriza a(s) juventude(s) e pode ser analisada, considerando, como referências fundamentais, a relação dos jovens com a família, com o trabalho e com o lugar da escola. No caso da família, o processo de autonomização está associado ao distanciamento da família de origem e à busca de constituir outra. Já a escola é um lugar que cumpre um papel-chave, no processo de socialização e de institucionalização do saber adquirido (através da certificação). Ambos são elementos de referência, no ritual do "vir a ser" adulto, em nossa sociedade. O trabalho, por sua vez, está diretamente associado à possibilidade, por hipótese, de conquista de autonomia material. A própria ideia de autonomia, na sua relação com trabalho, contudo, pode e deve ser problematizada, uma vez que a remuneração da força de trabalho não tem garantido que a grande maioria dos trabalhadores possa, efetivamente, sustentar a si e às suas famílias. Assim, ingressar no mercado de trabalho não significa, necessariamente, garantia de autonomia.

Embora a ideia de "transição" permita capturar elementos importantes desse período de vida, ela traz consigo uma limitação que merece destaque. Estudiosos do tema têm insistido 
que, de uma maneira geral, nas ações dirigidas aos jovens, estes não são considerados como sujeitos capazes de desenvolver e exercer um protagonismo próprio, relacionado ao seu tempo presente. Isto é, há sérias restrições em se aceitar a ideia de que os jovens têm condições de realizar e processar a sua experiência de ser jovem. Essa dificuldade poderia ter suas raízes na própria imagem que se produz acerca da fase jovem (e da juventude), como um estágio de "vir a ser". É nesse sentido que a ideia de transição acabaria por negar a experiência singular, vivida pela juventude, aqui e agora.

Assim, por um lado, a reflexão a respeito da defesa do "protagonismo juvenil" parece adequada, porque reforça a dimensão de não assujeitamento do jovem à sociedade em que vive e também afirma a noção de que há uma experiência que não se restringe a uma passagem. Por outro, há que se ter cautela, em função de outros significados que também vêm acompanhando o discurso, a respeito do "protagonismo juvenil" ${ }^{2}$. Isso se verifica, em especial, quanto ao seu uso conservador e economicista, que responsabiliza o jovem pelo seu futuro, desresponsabilizando, consequentemente, a sociedade e o Estado de suas tarefas em relação às novas gerações - discurso esse que é deveras útil, no contexto neoliberal.

No Brasil, embora com avanços significativos, as políticas públicas têm sido elaboradas, em geral, "para" os jovens, e não "com" eles. Além disso, a frequente abordagem do jovem como problema (para a sociedade e para si mesmo), como desvio, como desqualificado para a atuação pública ou como ameaça da construção e da consolidação da democracia dificulta a construção de uma perspectiva social positiva, permeada por um protagonismo juvenil.

Estudos indicam que a visão do jovem como problema está ancorada numa ótica de adaptação do jovem ao que dele se espera. Nesse sentido, a juventude vira um problema, quando não acontece a almejada transição das novas gerações para os valores, normas e comportamentos socialmente aceitos pelas forças sociais e políticas dominantes, garantidoras da ordem e coesão social (Abramo, 1997; Dayrell, 2003). É esse enfoque do perigo e da ameaça à coesão social que está na base da emergência e da multiplicidade de políticas para a juventude, em especial perante o desemprego maciço, observado nas últimas décadas.

Note-se que as políticas para a juventude têm, como público-alvo, justamente essa juventude excluída do trabalho formal e da escola. Em geral, as ações incluem a dimensão da qualificação profissional, combinada ou não à inserção no mercado de trabalho. Tais ações estão fortemente relacionadas à gestão do desemprego. Os jovens, nessa perspectiva, em vez de sujeitos de direitos são considerados sujeitos de assistência social. Além disso, o trabalho aparece como uma prática social, capaz de disciplinar o jovem, contribuindo para a diminuição dos riscos que ele, ocioso, potencialmente cria para a sociedade ${ }^{3}$.

O trabalho - compreendido com uma experiência individual e coletiva - incorpora, de forma dialética, dimensões objetivo-subjetivas, na sua relação com o tema complexo das relações entre juventude e autonomia, que é objeto central de reflexão deste artigo. De forma particular, reflete-se sobre o trabalho associado. Considera-se que este seja uma das perspectivas que se apresentam para a juventude, hoje, no seu processo de afirmação pessoal e coletiva, na sociedade.

2 Para uma análise crítica da ideia de protagonismo juvenil, ver Ferretti, Zibas e Tartuce (2004).

3 Sobre políticas públicas para a juventude, ver Sposito e Carrano (2003). 


\section{Juventude(s) e trabalho}

Não é difícil constatar que os jovens filhos e filhas da classe trabalhadora têm dificuldade de encontrar emprego, o que não significa que não trabalhem. Com a crise estrutural do emprego, o trabalho fixo foi substituído pelo trabalho assalariado temporário (geralmente sem vínculo empregatício) e pelo chamado "trabalho por conta própria", também precário. Não são poucos os jovens que, para não morrerem de fome, trabalham como homens e mulheres estátua, como "comedores de fogo" ou "vendedores de qualquer coisa", no sinal de trânsito. Também é comum que sejam encontrados jovens de "classe média" que, para ganhar algumas cervejas, complementar a renda e, quem sabe, conseguir se verem "livres" da tutela dos pais, se tornam percussionistas de um bloco de carnaval ou de uma escola de samba, por exemplo. Como será visto depois, o ingresso no mundo da cultura vem se constituindo como estratégia de trabalho e de sobrevivência, para os filhos de um amplo espectro da classe trabalhadora.

Por que fazer referência a juventudes? Ser um jovem trabalhador negro, nascido em Moçambique, na década 1980, não é o mesmo que ser um(a) jovem homossexual, nascido(a) no Brasil, na década de 1990. Essa última categoria, por sua vez, carrega uma cultura diferente de uma jovem do campo, que há dois ou três anos foi morar numa favela do Rio de Janeiro. Em relação à forma de inserção no mundo do trabalho, ser um jovem artesão francês, que vende brincos na praia do Leblon, não é o mesmo que ser um jovem que trabalha e vive na Comunidade de Remanescentes de Quilombos São José da Serra, localizado no município de Valença, RJ ${ }^{4}$. Como diz Santos (1996, p. 3), "[...] temos o direito de ser iguais quando a diferença nos inferioriza. Temos o direito de ser diferentes quando a igualdade nos descaracteriza". Nessas pequeno-grandes diferenças se está fazendo referência à dimensão de classe social: falando de jovens filhos da classe trabalhadora ou falando de jovens que vivem, confortavelmente, aguardando a herança de seus pais?

Da mesma maneira que se faz alusão a juventudes, podem-se abordar culturas que se entrelaçam e se manifestam no processo de trabalho. Da agroindústria canavieira paulista, por exemplo, em que a produtividade do corte de cana varia de 12 a 15 toneladas por trabalhador, participam jovens migrantes, geralmente nordestinos, que estão em busca de algum dinheiro. Nessa atividade de trabalho extremamente precária, além de a força física ser valorizada como fator de produtividade e, ao mesmo tempo, ser sinônimo de masculinidade, "[...] é interessante notar a combinação entre o corpo magro e musculoso apropriado para o corte de cana e certas marcas identitárias próprias da juventude atual: tatuagens, piercings, pequenos brincos e colares" (Condé \& Novaes, 2007, p. 65). É o que Canclini (1997) chamaria de culturas híbridas.

Com relação a isso, é pertinente a pergunta a respeito do que dizem as pesquisas sobre os sentidos que os jovens brasileiros atribuem ao trabalho. Para responder a essa interrogação, consideram-se, como base, as análises de Guimarães (2005, pp. 149-174), a partir dos dados da pesquisa "Perfil da Juventude Brasileira". Dois aspectos fundamentais emergem de sua análise. O primeiro é a centralidade do trabalho, nas preocupações dos jovens entre 16 e 24 anos. $\mathrm{O}$ segundo diz respeito aos sentidos atribuídos ao trabalho, pelos jovens. Quatro são os sentidos principais que aparecem (nesta ordem): trabalho como necessidade; trabalho como fonte de

\footnotetext{
4 Sobre a juventude quilombola, ver o vídeo documentário Sementes da memória: a juventude do Quilombo São José da Serra (Carrano et al., 2006).

5 O Perfil da Juventude Brasileira (2003) “[...] foi uma iniciativa do Projeto Juventude/Instituto Cidadania, coma parceria do Instituto de Hospitalidade e do SEBRAE. Foi realizada sob a responsabilidade técnica da Criterium Assessoria de Pesquisas, retomando e ampliando temas e questões investigadas em outubro de 1999, pelo Núcleo de Opinião Pública da Fundação Perseu Abramo" (Abramo \& Branco, 2005, p. 370). A metodologia e a sistematização dos dados desta pesquisa envolveram uma amostra de 3.501 jovens, de 198 municípios brasileiros, em 25 estados. Foi realizada entre 22 de novembro e 8 de dezembro de 2003 , dados que podem ser encontrados em Abramo e Branco (2005).
} 
independência; trabalho como crescimento; e, para poucos, o trabalho como autorrealização. Ao tentar entender as bases materiais dessas representações, a autora identifica "a longa experiência do jovem brasileiro com o trabalho". Trata-se, portanto, "da juventude trabalhadora brasileira" ${ }^{6}$. Guimarães (2005) conclui:

[...] mais além dessas representações comuns, erigem-se formas de conceber e outorgar valor ao trabalho (fundando-se seja na ética, seja na necessidade, seja na arguição do direito) e padrões de interpretar o significado subjetivo do seu resultado (seja como provedor de necessidade, seja como produtor de independência, crescimento ou autorrealização), os quais, longe de descentrarem o trabalho, permitem entrever a pluralidade de significados produzidos no seio desse grupo de jovens (p. 171).

Considerando essa análise, pode-se perceber a proeminência do significado do trabalho e a sua dimensão como necessidade - significado este que acompanha aquele atribuído por adultos trabalhadores. Afinal, não é, principalmente, o trabalho como liberdade, em sua dimensão ontocriativa, que é experimentado na sociedade capitalista. Isso nos coloca questões importantes, para reflexões relativas à suposta transição dos jovens brasileiros para a vida adulta. A referência que se faz aqui é a de jovens adultos, pois um número considerável deles já trabalha e contribui decisivamente com a renda familiar. As questões colocadas para esses jovens, portanto, no que diz respeito à sua autonomia são permeadas de contradições.

Os jovens têm sido os principais atingidos com o desemprego. Para Branco (2005), nos países emergentes, "[...] a possibilidade de o jovem tornar-se desempregado é 3,8 vezes maior que a de um adulto a partir de 25 anos" (p. 129). No horizonte da educação, na ótica do capital, desde muito cedo, dentro e fora de escola, são ensinadas as regras fundamentais para os jovens trabalhadores sobreviverem no mercado de trabalho e alcançarem o prometido sucesso na vida profissional: competir para vencer. Isso é alardeado como dogma para a vida, quer seja individualmente, quer seja com o seu "time" dentro da empresa, quer, ainda, para vencer as outras empresas. A dimensão solidária do ser humano fica reservada para ser cultivada na vida familiar, entre amigos ou em outros momentos, espaços e tempos da vida fora do trabalho. É claro que, por outro lado, o ambiente competitivo do mercado de trabalho capitalista invade, também, outras esferas da vida humana, produzindo uma cultura competitiva.

Para Razeto (1993), a economia não se torna solidária, apenas porque os homens são "bons" ou "conscientes", mas, fundamentalmente, quando o Trabalho se torna a categoria que norteia todo o processo produtivo. Ao se tornarem gestores de uma organização econômica associativa, os jovens trabalhadores podem tentar fazer, do processo de trabalho, um fator de satisfação de sua necessidade básica: a de ser senhor de seu trabalho, o que, em última instância, contribui para satisfazer, ainda que precariamente, sua necessidade de criação, participação e liberdade.

Apostar no jovem, como capaz de realizar e processar a sua experiência, é fundamental para qualificar os seus processos singulares, que os desafiam a associar-se, para produzir a vida de forma autogerida. Surgem, então, diversos questionamentos. De que modo a autogestão poderia contribuir, na construção da autonomia individual e coletiva desses jovens, em oposição à heterogestão (que caracteriza o trabalho assalariado)? No contexto da formação social capitalista, o que aprendem aqueles jovens que, ao enfrentarem a falta de oportunidades no mercado de trabalho, de forma solidária, se organizam de modo autogestionário, para produzir sua existência? O que eles têm a ensinar sobre relações socioeconômicas? O que precisam aprender sobre o mundo do trabalho, sobre as relações dos seres humanos com a natureza e consigo mesmos? Que contradições vivenciam? Como as processam? Que escola desejam e/ou necessitam? Que saberes estão desconstruindo? Que novos saberes estão construindo, nos processos associativos de produção da vida, que se inspiram nos princípios da

6 Na pesquisa Perfil da Juventude Brasileira (2003), 76\% situa-se na órbita do trabalho: 36\% estavam trabalhando e $40 \%$ declararam-se desempregados. 
autogestão? Como esses jovens, que experimentam uma forma de trabalho articulada a um movimento mais amplo, em defesa da autogestão, ressignificam o sentido de autonomia, em seus processos de transição para a vida adulta? Eles diferenciam-se de outros jovens, cuja autonomia financeira reduz-se a ter um pagamento, resultante da venda individual da sua força de trabalho? Em que medida organizações econômicas populares podem contribuir para a constituição de uma nova sociabilidade e para cultura do trabalho, diferente da lógica excludente do capital?

\section{Associativismo(s) e produção associada}

De uma maneira geral, o associativismo é entendido como ação coletiva de pessoas e grupos que se organizam em torno de ideais e objetivos. Seria possível dizer que os jovens se associam, de variadas formas e por diferentes motivos: porque se identificam com um determinado estilo de vida e/ou compartilham das mesmas concepções de mundo e de sociedade, ou porque querem experimentar e exercitar as mesmas práticas, reivindicar os mesmos direitos e objetivar a realização de interesses comuns etc. As organizações associativas podem ser de abrangência local, regional, nacional e internacional e, dependendo do contexto histórico, dos objetivos e do grau de organização interna dos grupos e classes sociais, podem ter curta ou longa duração.

Toma-se, como exemplo de associativismo, o caso do V Fórum Social Mundial (FSM), realizado em Porto Alegre, no ano de 2005, em âmbito internacional, evento que contou com 155 mil participantes, representando 135 países e 6.588 organizações associativas. Mesmo que o associativismo ocorresse apenas nos dias em que o FSM aconteceu, é importante não esquecer que os jovens transformaram o "acampamento da juventude" em "cidade autogestionária", na qual todas as pessoas se responsabilizaram pelo cuidado com a natureza, pelo cuidado de si e do outro.

Na Espanha, o movimento dos Okupas é outro exemplo de associativismo juvenil, que tem perdurado desde o início dos anos 1980. Uma vez que a Constituição prevê o direito de todos os espanhóis usufruírem de uma moradia digna e adequada, os jovens (geralmente desempregados) resolveram rebelar-se. Se existem edifícios abandonados, casas sem inquilinos ou o preço dos aluguéis é muito alto, a solução, para eles, é clara: ocupar! Nesse e em outros casos, a adesão e a permanência no grupo é algo voluntário; os princípios que regem a organização associativa, bem como as regras e normas de convivência são estabelecidos, formal ou informalmente, pelos seus integrantes. Por motivos políticos, econômicos, religiosos, recreativos ou de qualquer ordem, o associativismo tem, como característica, a construção de laços sociais, que são calcados na confiança, na cooperação e na reciprocidade, conferindo, aos jovens, o sentimento de pertencimento a um grupo.

Uma pesquisa sobre economia popular (Tiriba, 2001) indica que as estratégias associativas de trabalho e de sobrevivência, fundadas em relações de doação, cooperação e reciprocidade, têm sido fundamentais para preservação de melhoria da qualidade de vida de um grande contingente da classe trabalhadora. Nos bairros populares dos grandes centros urbanos, além da organização de festas e de outras formas que propiciam a troca de afetividade, jovens e adultos se associam para cuidar das crianças (em sua própria casa ou em creches comunitárias, criadas por eles próprios), para limpar o valão, para protestar contra a violência da polícia, enfim, para tentar garantir as condições mínimas de vida e para seguir vivendo. Como diz Cariola (1992), diante da ausência do Estado, a reprodução social dos setores populares exige a ativação de mecanismos de solidariedade, que vão desde ações espontâneas a práticas informal 
ou formalmente organizadas, no sentido de obter ganhos "extraeconômicos" necessários para a sobrevivência?

Pode-se inferir que existe uma grande diversidade de práticas solidárias que repercutem em diferentes estilos de associabilidade juvenil: "pedir cola na hora da prova, participar do mutirão para o conserto do telhado do vizinho, participar da organização sindical, participar do partido político ou da frente internacional para enfrentar o FMI (Fundo Monetário Internacional)" (Tiriba, 2004, p. 94). Como as pessoas não se associam apenas por uma "causa nobre", "[...] a questão é saber com quem nos associamos (se com o vizinho ou com o FMI) e com que critérios se estabelecem as regras do jogo (com relações de dominação ou igualdade)" (Tiriba, 2004, p. 93). Em outras palavras, nunca é demais lembrar que o associativismo não se apresenta, necessariamente, como uma prática progressista ou revolucionária. Os empresários também se associam, nos sindicatos de empregadores ou para fazer lobby no Congresso Nacional. Os jovens também têm se organizado em torno do tráfico de drogas ou em movimentos neofacistas, por exemplo.

Vale ressaltar que, indo ao encontro do projeto neoliberal, em que as relações entre Estado e sociedade se dão de forma tripartite (estado-sociedade-mercado), organizações associativas têm sido estimuladas a compor o chamado "terceiro setor" (Montaño, 2002) setor este que não pode se confundir com o movimento da economia popular solidária. No contexto da acumulação flexível, em que a crise do trabalho assalariado e o desmonte do Estado do Bem-Estar requerem novas formas de "inclusão social", os jovens são conclamados a se tornar "empregáveis", "empreendedores" e "patrões de si mesmo". Para Costa (2004, p. 252), consultor na área de educação para o empreendedorismo, "[...] educar é criar espaços para que o educando possa empreender, ele próprio, a construção do seu ser, em termos pessoais, sociais e profissionais". O empreendedorismo está relacionado a um "[...] conjunto de talentos, habilidades e capacidades requeridos das pessoas que se dispõem a desenvolver um negócio próprio". Entre as "virtudes empreendedoras", entendidas como novas atitudes diante da vida e do trabalho, destacam-se: visão positiva do futuro (otimismo), coragem de correr riscos calculados, proatividade, paixão pelo que faz, criatividade, assertividade e liderança (Costa, 2004). Nessa perspectiva, com a contribuição das organizações não governamentais, o Serviço Brasileiro de Apoio a Micro e Pequenas Empresas (Sebrae) desenvolve projetos educativos, no âmbito da educação básica e do ensino superior. O objetivo desses projetos é desenvolver uma mudança cultural, quanto às expectativas dos jovens, em relação ao mundo do trabalho, e educá-los, de maneira a torná-los jovens empreendedores. Assim, não há de se estranhar a existência de associações de "jovens empresários" e "jovens empreendedores". Ressalta-se que não é a esse tipo de "protagonismo juvenil" que se refere este artigo. A intenção, aqui, não é estimular e/ou fortalecer formas de trabalho que reproduzam a lógica excludente do capital.

O envolvimento dos jovens com a economia popular solidária ${ }^{8}$ pode indicar um caminho, potencialmente diferenciado, no sentido de relacionar juventude, trabalho e formação, e permitir que outros sentidos sejam atribuídos ao trabalho, a partir de outras experiências de trabalho9. É o que estão evidenciando experiências associativas como a da

\footnotetext{
7 Tomás Villasante (1994) considera que o "individualismo metodológico" e a "escolha racional” não são suficientes para explicar as causas do associativismo. Para ele, as pessoas se associam para encontrar, em outras pessoas e grupos, algo que não encontram em si como indivíduos isolados. Identifica que as associações dão suporte aos movimentos sociais e vice-versa, assim, "[...]se os movimentos se movem, as identidades das associações têm que estar em renovação contínua" (p. 11).
}

8 A Secretaria Nacional da Economia Solidária/MTE (2010) define a Economia Solidária como sendo "[...] um jeito diferente de produzir, vender, comprar e trocar o que é preciso para viver. Sem explorar os outros, sem querer levar vantagem, sem destruir o ambiente. Cooperando, fortalecendo o grupo, cada um pensando no bem de todos e no próprio bem. Compreende uma diversidade de práticas econômicas e sociais organizadas sob a forma de cooperativas, associações, clubes de troca, empresas autogestionárias, redes de cooperação, entre outras, que realizam atividades de produção de bens, prestação de serviços, finanças solidárias, trocas, comércio justo e consumo solidário. Nesse sentido, compreende-se por economia solidária o conjunto de atividades econômicas de produção, distribuição, consumo, poupança e crédito, organizadas sob a forma de autogestão".

9 Várias das informações sobre grupos de jovens trabalhadores associados no Brasil, referidas neste artigo, foram, gentilmente e de forma solidária, enviadas por componentes do grupo de discussão E-solidária, por via eletrônica, em outubro de 2007. 
Usina Catende ${ }^{10}$, na Zona da Mata (Pernambuco). Entre essa experiência, está a produção coletiva da semente de milho, através da Associação dos Jovens Filhos e Filhas dos Trabalhadores(as) do Projeto Catende Harmonia, denominada Puama, cujo significado é "Rosas que nascem das pedras". Lá, na área rural, existem 2.234 jovens, entre 16 e 25 anos. Pouco a pouco, evidencia-se, "[...] para o conjunto dos que fazem o projeto autogestionário da Usina Catende, o desafio de uma geração que encarna para si um futuro de trabalho, diferente daquele passado, a que seus pais foram submetidos" (Lima, Schau \& Pickersgill, 2006, p. 8). Assim, no horizonte do trabalho emancipado, não se está fazendo referência, aqui, aos jovens que se associam para se tornarem jovens empresários, mas jovens trabalhadores que buscam, na produção associada, a reprodução ampliada da vida (e não do capital).

Como manifestação do associativismo, o conceito de "produção associada" está diretamente relacionado ao mundo do trabalho, sendo entendido como trabalho associado ou processo em que os trabalhadores e trabalhadoras se associam, na produção de bens e serviços. De acordo com a concepção marxiana, a produção associada (ou trabalho associado) pode ser compreendida como a unidade básica da "sociedade dos produtores livres associados", fundada na propriedade coletiva dos meios de produção, na gestão coletiva do processo de trabalho e na distribuição igualitária dos frutos do trabalho. Embora, na obra de Marx, a questão da produção associada não seja tratada de forma sistemática, é possível encontrar algumas referências importantes sobre isso. $\mathrm{Na}$ verdade, ainda que a associação cooperativa seja uma ideia vinculada ao socialismo de Owen, essas iniciativas não são condenadas por Marx. No Discurso inaugural, da fundação da Associação Internacional de Trabalhadores (AIT), em 1864, ele afirma que, mesmo limitado na sociedade de classes, "[...] o trabalho associado, que maneja suas ferramentas com mão hábil e entusiasmada, espírito alerta e coração alerta" (apud Bottomore, 1993, p. 20), representa a negação do trabalho assalariado.

Marx condena, no entanto, a desvirtuação que os "porta-vozes e filantrópicos da burguesia" fazem sobre o papel das cooperativas, no processo de emancipação da classe trabalhadora. Mesmo reconhecendo as associações cooperativas como um fato vitorioso da economia política da classe trabalhadora, ele alerta sobre a influência da burguesia, no movimento cooperativista, que a utiliza a serviço de interesses estranhos ao proletariado. Também chama a atenção para o fato de que experiências associativas não podem se restringir a um "[...] estreito círculo dos esforços casuais de grupos de trabalhadores" (apud Bottomore, 1993, p. 20). Por sua vez, argumentando contra o revisionismo de Bersntein, Rosa Luxemburgo analisa que as cooperativas, por si só, são incapazes de transformar o capitalismo. Para ela, "[...] las cooperativas, sobretodo las de producción, constituyen una forma híbrida en el seno del capitalismo. Se las puede describir como pequeñas unidades de producción socializadas dentro del intercambio capitalista" (Luxemburgo, 1976, p. 92). A autora argumenta que, na economia capitalista, o intercâmbio domina a produção, o que significa que a produção depende, em grande medida, das leis do mercado e, portanto, sim, nas cooperativas de produção "[...] siguen predominando los intereses obreros, terminan por disolverse" (Luxemburgo, 1976, p. 92).

O espaço deste artigo não permite resgatar a discussão, no campo do marxismo, sobre os significados políticos da propriedade ou da posse coletiva dos meios de produção no interior da sociedade capitalista ${ }^{11}$. Mesmo assim, vale registrar que, ao longo da história do capitalismo, muitas vezes os trabalhadores tomaram para si as rédeas da produção da vida, reinventando o trabalho e as relações de convivência social e política. Salvaguardando as particularidades dos

10 A Usina de Catende - com 25 mil hectares, distribuídos por cinco municípios (Palmares, Jaqueira, Xexéu, Catende e Água Preta) e com 4 mil famílias de trabalhadores (envolvendo uma população de 12 mil pessoas) -, após o pedido de falência pelos trabalhadores, em 1995, passou a ser uma empresa de autogestão e tornou-se um ícone da luta dos trabalhadores, pelo controle do seu próprio destino.

11 Sobre essa questão, ver Tiriba (1997). 
diferentes espaços-tempos históricos, destacam-se a experiência dos falanstérios ${ }^{12}$, desenvolvidos na França e também no Brasil (inspirados em Charles Fourier), e a Comuna de Paris, em 1871. Do século XX, podem-se mencionar, por exemplo, o controle operário e os Soviets de representantes operários, camponeses e soldados na Rússia (1905 e 1917); a Guerra Civil Espanhola (1936-1939); as experiências de autogestão, na Iugoslávia (1950); conselhos operários surgidos na Hungria (1956) e na Polônia (1956, 1970), com o movimento Solidarnosc (1980); e a Revolução dos Cravos, em Portugal (1974). Também, com diferentes graus de controle da produção, pelos trabalhadores, na América Latina e Caribe, podem ser indicadas, entre outras, as Revoluções Cubana (1959) e Nicaraguense (1979), algumas curtas experiências, vividas na Bolívia, Peru e Chile (1972), e a dos indígenas em Chiapas (desde 1994). Mais adiante, outras tantas revoluções surgiram, entre os séculos XX e XXI, tendo também os jovens como protagonistas dos processos de tessitura de uma cultura do trabalho, distinta da cultura do capital.

\section{Culturas do trabalho e autogestão}

Todo trabalho é trabalho social, o que quer dizer que, ao se relacionar com a natureza e modificar o mundo natural, humanos entram em contato com outros humanos, recriando regras de convivência social que têm, como referência, a forma de propriedade dos meios de produção. No capitalismo, assim como os adultos, os jovens trabalhadores vendem sua força de trabalho para o proprietário privado dos meios de produção, trocando-a por um salário. Em outras palavras, o trabalho torna-se uma mercadoria e, nessa "troca", o proprietário da força de trabalho há de satisfazer o desejo do empresário: a realização do lucro.

Quando se fala em trabalho associado, tem-se, como referência, uma cultura do trabalho autogestionário, na qual as relações de convivência se dão de maneira distinta da lógica do capital. O galpão, por exemplo, as máquinas e demais instrumentos de trabalho pertencem aos jovens trabalhadores (ou estão em via de pertencer). Nesse sentido, são eles que definem como vai se dar o processo de produção, qual o ritmo e a intensidade do trabalho, o que e para quem se vai produzir, por quanto será vendido o produto, com que critérios vão distribuir os excedentes, etc. Diferentemente da racionalidade da economia capitalista, o produto final não se desgarra de seu produtor; não pertence ao empresário, mas aos próprios trabalhadores. Em síntese, a organização da produção, pelos trabalhadores associados, pressupõe a criação de uma cultura do trabalho distinta da que vivemos no trabalho assalariado (seja ele fixo, seja temporário, com ou sem carteira assinada).

O conceito de cultura do trabalho abarca o conjunto de códigos, padrões, normas, saberes, crenças, valores e criações materiais, que regulam as ações e comportamentos das pessoas, no processo de trabalho e no processo mais amplo de produção da vida social. Compreende os elementos materiais (instrumentos, métodos, técnicas, etc.) e simbólicos (atitudes, ideias, crenças, hábitos, representações, costumes), partilhados pelos trabalhadores e trabalhadoras, tendo em conta suas especificidades de classe, gênero, etnia, religiosidade e geração. Nessa compreensão, vale lembrar que a apropriação coletiva dos meios de produção, por si só, não garante uma nova cultura do trabalho, pois as diferentes maneiras de pensar, sentir e se relacionar com o trabalho têm como pano de fundo o papel dos sistemas simbólicos na vida social e, em especial, os valores morais atribuídos ao trabalho (veiculados pelos meios de comunicação, pela escola, família, igreja, sindicato e outras instituições que modulam modos

12 Falanstérios são uma espécie de edifício-cidade onde as pessoas trabalham apenas naquilo que desejam e segundo suas vocações. Os falanstérios foram inspirados na proposta utópica de Charles Fourier (1772-1837), filósofo e economista político francês, que defendeu o fim da dicotomia entre trabalho e prazer. Nos falanstérios, os bens são distribuídos conforme a necessidade. A divisão das riquezas produzidas é feita, considerando-se a quantidade e a qualidade do trabalho de cada um (Tiriba, 2008, p. 91). 
de vida e relações entre grupos e classes sociais). É possível observar que, no Brasil, diversas culturas do trabalho sobrevivem, convivem e/ou se tornam subordinadas à cultura do capital. Entre elas, destacam-se a dos quilombolas, caiçaras e indígenas. Por isso, seria mais adequada a referência a juventudes e trabalhos, no plural!

Quando se pensa em uma cultura do trabalho fundada na autogestão, como alternativa ao desemprego e à precarização do trabalho, o que se está querendo dizer? No sentido do termo, restrito à dimensão socioeconômica autogestão é uma relação que se fundamenta na propriedade e/ou posse coletiva dos meios de produção, de bens e serviços, e na participação ativa dos trabalhadores, nas decisões da organização. Isso teria, como pressuposto, o controle coletivo e autônomo das relações que os jovens trabalhadores estabelecem com a natureza e entre si, no processo de produção. Na verdade, autogestão é um conceito (e uma prática social) que está relacionado com a perspectiva de uma forma de organização social, em que as pessoas têm autonomia e autodeterminação, não apenas da gestão do trabalho, mas em todas as instâncias das relações econômico-sociais. Com base nessa compreensão, a autogestão tem o ideário da superação das relações de produção capitalistas e a constituição de sociedade socialista/autogestionária.

De acordo com o seu significado etimológico, a palavra autogestão é a tradução literal da palavra servo-croata samoupravlje (samo, equivalente eslavo do prefixo grego "auto", e upravlje, com sentido aproximado de "gestão"). Guillerm e Bourdet (1976) indicam que autogestion só aparece na língua francesa no início dos anos 1960, para identificar a experiência política, econômica e social da Iugoslávia de Tito, em sua ruptura com o stalinismo (anos 1950). Na França, com os acontecimentos de Maio de 1968, autogestão passou a ser um termo para se referir às práticas sociais alternativas ao capitalismo, tornando-se palavra de ordem nas lutas reivindicatórias, no âmbito de todas as esferas da vida social. No livro Controle operário, conselhos operários, autogestão, Mandel (1988, p. 43) conta que, nesse contexto, "[...] os estudantes recorreram à tradição marxista revolucionária e fizeram reivindicações tais como: 'controle estudantil', 'poder estudantil', 'autogestão' das escolas universitárias".

Vale ressaltar que as experiências com as quais os trabalhadores se associam, na produção, não acontecem apenas em momentos "revolucionários", ou seja, em momentos em que a conquista do Estado está em jogo. Nos dias atuais, em que o regime de acumulação flexível repercute na crise estrutural do trabalho assalariado, pode-se perceber que o trabalho associativo e autogestionário apresenta-se, também para os jovens, como forma de driblar o desemprego e a pobreza. No contexto do desmonte do Estado do Bem-estar Social, as formas não capitalistas de produção ganham relevância (Santos, 2002).

$\mathrm{Na}$ verdade, ainda não se tem dados empíricos suficientes para saber em que medida, na contemporaneidade brasileira, os grupos de jovens trabalhadores orientam-se pelos princípios da economia popular solidária ou se constituem-se como jovens empreendedores. Mas, qual a diferença entre essas duas perspectivas econômicas? Os princípios da economia popular solidária estão calcados nos próprios princípios da autogestão: a) apropriação coletiva dos meios de produção; b) a gestão democrática das decisões pelos trabalhadores/as; e c) decisão coletiva sobre os rumos da produção e sobre a forma de utilização dos excedentes (sobras). Como foi referido, a educação para o empreendedorismo, hoje tão em voga, apregoa que o jovem deve tomar iniciativa e criar soluções alternativas à falta de empregos, tornando-se o "patrão de si mesmo" e, se possível, gerar novos empregos, ou seja, contribuir para a exploração da força de trabalho alheia. Nesse sentido, não se reivindica o empreendedorismo como alternativa para os jovens trabalhadores (desempregados), pois sua racionalidade econômica está diretamente relacionada à precarização do trabalho assalariado, o que se materializa pelo aumento crescente do trabalho assalariado temporário, sem vínculo empregatício e sem direitos sociais. Sem dúvida, é preciso "separar o joio do trigo" e examinar em que condições tem-se dado a (re)inserção ou "inclusão forçada" (Fontes, 1997) dos jovens 
na economia. Também é preciso estar "de olho" nas falsas cooperativas, as cooperfraudes e coopergatos (os mais novos mecanismos da acumulação flexível) ${ }^{13}$. Quanto às experiências associativas, cuja racionalidade econômica coincide com economia popular solidária, acreditase que elas só fazem sentido se associadas a movimentos sociais que buscam fortalecer a hegemonia do trabalho sobre o capital.

\section{Juventude, cultura e economia popular solidária}

A grande quantidade de jovens trabalhadores músicos, que, em busca de ganhar alguns trocados, reúnem seus instrumentos para "invadir" os bares da cidade, é um indício da existência de diferentes experiências de economia popular solidária, em que os jovens articulam trabalho e cultura. Entre eles, podem ser citados: os Dançarinos de rua (de Niterói), o Joinha Filmes (de São Paulo), o Musik Fabrik (cooperativa de jovens artesãos/ãs e instrumentalistas no Rio de Janeiro). Vale destacar, ainda, o trabalho do Núcleo Serigráfico (Bairro Alvorada, em Cuiabá) e do novo Salão de Beleza (no Jardim Vitória, em Cuiabá). Em Recife, existe a Rede de Resistência Solidária, na qual os jovens associam trabalho, cultura, lazer e comunicação. No Espírito Santo, participa do Fórum da Economia Solidária o grupo chamado Olho da Rua, com atuação na área de publicidade, jornal, revista, rádio comunitária, etc. Ainda nesse estado, há o Grupo de Cultura Afro Kisile, com dez anos de caminhada, que faz apresentações culturais (dança e música) e, além disso, produz roupas, bonecas e acessórios afro, e faz tranças em eventos. Em Salvador, têm-se, entre outros, o Fulô Produções - Associação de Jovens Produtores Culturais e o Grupo Informal de Jovens de Calabetão, que faz pinturas em camisetas.

A familiaridade e o conhecimento que os jovens desenvolvem, em relação à informática, têm-lhes gerado um capital cultural que também tem servido de base para gerar formas solidárias de trabalho. É o caso da Cooperativa Dinâmica Visual Design Multimídia, formada por 20 jovens (18 a 27 anos), muitos deles moradores da periferia de Santo André. Os jovens são apoiados pela Incubadora Pública de Economia Solidária, do Departamento de Geração Trabalho e Renda, da Secretaria de Desenvolvimento e Ação Regional da Prefeitura Municipal de Santo André. Outro exemplo é o da Cooperativa de Informática Alpha ${ }^{14}$, já desincubada pela Incubadora Tecnológica de Cooperativas Populares - Universidade de São Paulo (ITCP USP), formada por jovens do Capão Redondo e Campo Limpo, periferia da Zona Sul de São Paulo e que presta serviços, como manutenção e assessoria em hardware; projeto, implantação, manutenção e assessoria em rede de computadores, software livre, web design, etc. Está sendo também incubado o Microlhar, composto por jovens da periferia da cidade de São Paulo, com o objetivo de contribuir para a democratização dos meios de comunicação. $O$ grupo ministra oficinas de Leitura crítica de imagem, no Centro de Referência em Economia Solidária, na Zona Sul. Eles realizam filmagens e já produziram documentários.

Importante registrar que os jovens trabalhadores associados estabelecem diversos tipos de parcerias. Sabe-se que um grande número de grupos recebe algum tipo de apoio de igrejas, organizações não governamentais, centrais sindicais e outras entidades dos movimentos sociais, incubadoras universitárias e, ainda, dos governos municipal, estadual e federal. Citamos alguns exemplos que ajudam a perceber as várias possibilidades de constituição de redes sociais. No Mato Grosso, os jovens da cidade de Cáceres, que se organizam em torno do Movimento Nacional de Meninos e Meninas de Rua (MNMMR), estão planejando a criação de um empreendimento econômico solidário e também lutaram pela aprovação de uma Lei Municipal

13 Note-se que os próprios jovens se questionam sobre as diferenças entre empreendedorismo e economia popular solidária. Isso ficou evidenciado em encontro organizado pela ONG Ação Educativa, Fundação Friedrich Ebert e Projeto Redes e Juventudes, em Recife, em 2006, com representantes de 20 empreendimentos produtivos de jovens (Tommasi, Nogueira \& Corrochano, 2007).

14 Ver sítio na Internet http://coopalpha.com.br/index.html 
de Economia Solidária, por iniciativa popular. Outro exemplo que expressa a natureza e amplitude dessas redes de solidariedade é o caso da Cooperativa de Costura (Coocas), em Cariacica, na região metropolitana de Vitória (Espírito Santo). Esse grupo foi fomentado pela Associação de Mulheres Unidas de Cariacica Buscando a Libertação (Amucabuli), contou com a assessoria da Secretaria Municipal de Desenvolvimento e produz peças íntimas, em um espaço cedido pela igreja católica. A Prefeitura de Fortaleza/Ceará criou uma "célula de juventude e economia solidária", também ancorada na Secretaria de Desenvolvimento Econômico, que desenvolveu o Credi-Jovem, alicerçado nos princípios da economia solidária. No caso de o projeto ser aprovado, existe o financiamento e acompanhamento, por parte da secretaria.

Receber apoio de uma entidade ou instituição é um elemento fundamental para a sobrevivência dos grupos, o que, muitas vezes, pode repercutir na criação de uma dependência econômica. No Mato Grosso, a Pastoral da Juventude Rural (PJR), em parceria com a Universidade Estadual de Mato Grosso (Unemat) e a Fundação Unitrabalho, está apoiando o processo de constituição de uma cooperativa de Jovens Rurais. Essa cooperativa envolve cerca de 400 jovens, que atuarão em oito municípios do norte do Estado, produzindo mudas de essências nativas e medicinais. Essas mudas serão trocadas com as famílias dos pequenos agricultores, por outros produtos da terra. Ainda na área rural e na mesma perspectiva da economia solidária, encontra-se a Cooperativa Popular de Alimentos Vila Verde (Coopavv), que produz hortaliças (Mussurunga/Salvador), com o apoio a Associação de Finanças Solidárias (Bansol), vinculada à Escola de Administração da Universidade Federal da Bahia (UFBA). Essa cooperativa tem como parceiras duas outras instituições universitárias: a Universidade do Estado da Bahia (Uneb), através da Incubadora Tecnológica de Cooperativas Populares (ITCP), e uma instituição privada - a Universidade Salvador (Unifacs). Também na Bahia, a Agência de Desenvolvimento Solidário (ADS/CUT) apoia o Bijou Fashion (em Retirolândia), que é um grupo que trabalha como "biojoias", aproveitando a diversidade da região; e a Cooperativa Regional de Jovens da Região Sisaleira (Cooperjovens), em Araci, que nasceu a partir dos sindicatos de trabalhadores rurais e hoje produz artefatos em papel reciclado. Nessa região do sisal, também há o Grupo de Produção de Cabochard (em Valente), que se dedica à produção de sabonete, molho de pimenta e horticultura (com apoio da Apaeb). Quando se trata de um Consórcio Social da Juventude - linha de ação do Ministério do Trabalho e Emprego (MTE) para implementação do Programa Nacional de Estímulo ao Primeiro Emprego para Jovens $(\mathrm{PNPE})^{15}$, a relação com a economia solidária se dá quando são criadas associações e cooperativas autogeridas. É o caso da cadeia produtiva do skate com marca Epidemia, que existe desde 2006, como resultado do Consórcio. Os jovens organizam-se em cinco núcleos, na Grande Porto Alegre, para fabricar produtos relacionados ao skate: tênis, roupas, mochilas e o próprio skate. Além do Ministério do Trabalho, os jovens têm o apoio de várias entidades do Rio Grande do Sul: Instituto Murialdo, Fundação Pão dos Pobres, Escola Técnica José César Mesquita/Sindicato dos Metalúrgicos POA, Associação Reviver e Escola de Trabalhadores 8 de Março.

Infelizmente, o espaço deste artigo não é suficiente para contemplar todas as informações coletadas sobre jovens trabalhadores que se associam na produção da vida. Uma questão de pesquisa seria analisar se condições objetivas e subjetivas, nas quais existe a produção associada, permitem que os jovens descubram um novo sentido do trabalho - não mais como tripalium ${ }^{16}$. Todo cuidado para não romantizar ainda é pouco! Se, de um lado, as

15 Para uma análise do Programa Primeiro Emprego e das ações que o integram, ver Cunha e Silva (2006). Recentemente, todos os programas existentes, voltados para a juventude, foram unificados, gerando o Programa Nacional de Inclusão de Jovens (ProJovem), que foi subdividido em quatro modalidades: ProJovem Adolescente, ProJovem Urbano, ProJovem Campo e ProJovem Trabalhador. A modalidade ProJovem Trabalhador unificou os programas Consórcio Social da Juventude, Juventude Cidadã e Escola de Fábrica. A gestão do ProJovem é compartilhada entre a Secretaria-Geral da Presidência da República, por meio da Secretaria Nacional de Juventude, e os ministérios do Trabalho e Emprego, do Desenvolvimento Social e Combate à Fome e da Educação (http://www.presidencia.gov.br/estrutura_presidencia/sec_geral/noticias/ultimas_noticias/not_05092007).

16 "Tripalium era um instrumento feito de três paus aguçados, algumas vezes ainda munidos de pontas de ferro, no qual os 
experiências associativas são uma alternativa real ao desemprego e à precarização do trabalho, de outro, essa forma alternativa de produzir a vida social não leva os jovens trabalhadores associados ao paraíso. Os jovens estão em todos os cantos do mundo, mas, como diz o ditado popular, "uma andorinha só não faz verão". Encanta, nesse sentido, a possibilidade de uma autogestão no trabalho e na vida em sociedade; no entanto, a vida real tem demonstrado que as experiências isoladas de trabalho associado tendem a fracassar, em função da sua inviabilidade econômica. Dado que a unidade produtiva (de bens materiais e/ou imateriais) se situa numa sociedade capitalista, os jovens trabalhadores não vão conseguir ser livres da imposição das chamadas "leis do mercado" (capitalista), que nada mais são do que as próprias "leis da selva". Sendo o Estado (capitalista) um espaço de contradições, a economia (popular) solidária torna-se também, no seu interior, um espaço de disputa de projetos políticos ${ }^{17}$.

Para poder driblar o "deus" Mercado, os jovens trabalhadores se veem diante de um grande desafio: participar, construir e fortalecer o que, hoje, se denomina "mercado solidário", ou seja, um espaço no qual se dá a troca de bens e serviços, entre os diversos grupos de produtores associados, do campo e da cidade. Para o nicaraguense Orlando Nuñez, assim como os empresários tiveram que se associar, para que as relações de produção capitalistas se tornassem hegemônicas, também os grupos de trabalhadores associados - jovens e adultos precisam se organizar em torno de uma "economia popular associativa e autogestionária". No Manifesto associativo e autogestionário, Nuñez (1998) propõe o fortalecimento de um bloco social, composto por movimentos sociais, famílias, comunidades locais e associações autogestionárias de produtores. Ele defende, também, que se construa um sistema comunitário que potencialize relações de cooperação e solidariedade. Apesar de todas as dificuldades, o movimento por uma economia popular solidária pode ser um bom começo!

\section{À guisa de conclusão: sentidos do trabalho e dos processos educativos}

Organizada pelo Fórum Brasileiro de Economia Solidária (FBES) e pela Secretaria Nacional de Economia Solidária (Senaes/TEM), foi realizada, em dezembro de 2005, a I Oficina Nacional de Formação em Economia Solidária. Nela, foi possível, para os 40 representantes de 22 estados diferentes (incluindo experiências de âmbito nacional), fazer uma primeira sistematização das práticas e dos desafios educativos, quanto a: a) contribuições, limites, dificuldades e lições das experiências de formação de formadores e de formação para empreendimentos econômicos solidários; b) princípios da educação/formação em economia solidária; c) conteúdos a serem trabalhados, nas formações em economia solidária; d) elementos metodológicos; d) sistematização das práticas educativas solidárias; e) elementos para uma política pública de formação em economia solidária. A II Oficina ocorreu em abril de 2007, também em Brasília, na qual estiveram presentes representantes de cerca de 50 experiências de formação. Avançando na discussão político-pedagógica, na ocasião, foram criadas redes estaduais e uma rede nacional de formação. Embora nenhuma delas tenha tratado, especificamente, sobre juventude e trabalho associado, é importante destacar alguns de seus princípios educativos:

[...] fortalece(r) a organização dos trabalhadores e trabalhadoras em torno de um projeto econômico-social que privilegia a valorização do trabalho (e não do capital). Para tal, ao

agricultores bateriam o trigo, as espigas de milho, para rasgá-los, esfiapá-los. A maioria dos dicionários, contu do, registra tripalium apenas como instrumento de tortura, o que teria sido originalmente, ou se tornado depois. A tripalium se liga o verbo do latim vulgar tripaliare, que significa justamente 'torturar"” (http://pt.wikipedia.org/wiki/Tripalium).

17 No que diz respeito às políticas públicas de economia solidária no Governo Lula, foi criada, no interior do Ministério do Trabalho e Emprego, em julho de 2003, a Secretaria Nacional de Economia Solidária (SENAES), coordenada pelo professor Paul Singer. Na Venezuela, no Governo Chaves, foi criado, em 2005, o Ministério da Economia Popular, com o objetivo de criação de cooperativas para fazer frente às empresas consideradas improdutivas. 
mesmo tempo em que se substancia na denúncia da exploração do trabalho, na crítica à lógica excludente da economia capitalista e ao sistema opressor que fragmenta o ser humano (dividindo a sociedade entre "compradores e vendedores de força de trabalho"), os processos educativos inspirados na Economia Solidária anunciam uma nova sociabilidade, uma nova sociedade, uma nova forma de produção da vida.

[...] Como nos demais processos autogestionários de produção da vida, a educação/formação tem como perspectiva o trabalho-criação, no qual homens e mulheres têm o controle sobre todo o processo (produção, administração, beneficiamento, distribuição, troca e consumo ético/crítico/consciente dos frutos do seu trabalho). Ao invés da acumulação privada da riqueza, a finalidade da atividade econômica é o próprio ser humano; neste sentido, como nos demais processos de trabalho que têm a Economia Solidária como musa inspiradora, os processos educativos fundamentam-se no exercício prático da democracia, contribuindo para que todas as pessoas envolvidas, reconhecidas como sujeitos de conhecimento, possam resgatar os sentidos do trabalho, construindo sua autonomia como atores econômicos, construtores de história e de cultura (MTE, 2006, pp. 15-16).

Sabe-se que, nas experiências de produção associada, os jovens vivenciam, de forma simultânea e contraditória, o trabalho como necessidade e o trabalho como liberdade. Aliás, qualquer forma de trabalho assume tais dimensões e de forma articulada. A primeira está associada à condição do ser humano que necessita trabalhar para garantir a sobrevivência, como ser biológico e social. A segunda diz respeito à dimensão livre e criativa do trabalho. Essa vivência necessita ser sistematizada e analisada coletivamente pelos sujeitos, para que a semente do "novo" possa, contraditoriamente, germinar no próprio solo que alimenta o "velho". Nesse sentido, a ação dos jovens, nas organizações econômicas associativas, precisa se tornar práxis reflexiva. Esse é um ensinamento central dos coletivos que vêm construindo uma "outra economia". Para fazer a sua própria história, é necessário que homens e mulheres desenvolvam uma ação consciente, no sentido de transformar estruturas. Estas, porque foram socialmente produzidas, são históricas e, consequentemente, podem ser transformadas. Saliente-se que a necessidade de os jovens refletirem criticamente sobre a sua experiência de trabalhar de forma associada, em tempos de crise civilizatória do capital, reveste-se de uma importância histórica singular, para esse jovem e para a sociedade como um todo. Como indica Abramo (1997),

[...] a juventude, vista como categoria geracional que substitui a atual, aparece como retrato projetivo da sociedade. Neste sentido, condensa as angústias, os medos assim como as esperanças, com relação às tendências sociais percebidas no presente e aos rumos que essas tendências imprimem para uma conformação social futura (p. 29).

Assim, trata-se de analisar, com os próprios jovens trabalhadores associados na produção vida, que sentidos do trabalho estão sendo produzidos, em suas experiências, no contexto da crise contemporânea do trabalho assalariado. É sua própria condição de jovem, pertencente à classe que vive do trabalho, que, na prática, está sendo problematizada. Assim, essa questão precisa se tornar objeto de conhecimento. Estar-se-ia produzindo um sentido para o trabalho, que vai além do trabalho como estratégia de sobrevivência?

Talvez, para os jovens trabalhadores associados, os processos de trabalho tornam-se ainda mais educativos, porque, entre tantas coisas, aprendem que é preciso não apenas driblar o desemprego e a lógica excludente do mercado capitalista, mas também fortalecer processos constituintes de outras formas de produzir a vida. É ilustrativo, nesse sentido, o que disseram os jovens do projeto Epidemia. Eles afirmaram que, se tivessem a possibilidade de ter acesso a um emprego hoje, não largariam o Projeto, por acreditarem que ele vai crescer muito e, além disso, porque o mercado de trabalho (assalariado) explora bastante. Os donos das empresas, segundo eles, ganham muito em cima dos funcionários, o que não buscam no mercado de trabalho. Informam que, quando estiverem mais qualificados, sabem que irão "lucrar" bastante e isso será dividido em partes iguais, para todos que trabalharem na organização econômica associativa. Dizem também que "[...] o lucro com a serigrafia é um jogo aberto, princípio da Economia 
Solidária: dividir em partes iguais" (Informação verbal) ${ }^{18}$. Tais falas dão a dimensão processual de formação em andamento, na própria prática, e, portanto, contêm elementos de um "novo" que emerge no meio do "velho". Parafraseando Gramsci (1982, p. 137), o objetivo da educação não pode consistir em os jovens se tornarem qualificados, no sentido de obter as competências básicas para a empregabilidade ou para o empreendedorismo, mas que cada um deles possa se tornar "governante" do seu trabalho, dos rumos da organização econômica, da sociedade, do mundo. Nessa perspectiva, dada a relação extrínseca entre projeto educativo e projeto societário, os jovens demandam uma sólida formação geral, articulada com formação específica para o trabalho. Para Nascimento (2005, p. 58), faz-se necessário formar o trabalhador autogestor no trabalho (formação técnica), na cultura (formação social e política) e na vida social em geral (cultural e moral). No cotidiano das experiências de trabalho associado, tratase, nesse contexto, de responder ao desafio de incorporar projetos e tempos de formação.

À escola que recebe os jovens trabalhadores, cabe repensar sobre sua tarefa específica, para permitir que objetivem e problematizem as vivências juvenis no mundo do trabalho ${ }^{19}$. Tal problematização e, ao mesmo tempo, legitimação dos saberes da experiência dos jovens trabalhadores associados é questão-chave ${ }^{20}$. Uma hipótese que se pode levantar é que ressignificar o trabalho dos jovens é, simultaneamente, ressignificar o sentido da escola como instituição social, mas, também, como ela é percebida hoje, pelos próprios jovens que estão experimentando trabalhar de forma associada. Pode-se pensar, por exemplo, na ideologia das competências, da empregabilidade e do empreendedorismo, que está permeando projetos político-pedagógicos de formação de trabalhadores. Problematizar o trabalho significa problematizar as relações entre escola e sociedade, atuais e a futuras. Trata-se, nes se processo, de enfrentar também, além do conteúdo e forma dos projetos pedagógicos, o desafio do tempo para estudar. O tempo dedicado a trabalhar para sobreviver invade aquele necessário para conhecer o mundo e descobrir o trabalho como liberdade. Como sinaliza Gramsci, "[...] a escola, quando funciona quando seriedade, não deixa tempo para a oficina e, vice-versa, quem trabalha seriamente apenas através de um enorme esforço de vontade de se instruir. [...] Encaixá-las uma na outra, assim como estão fazendo é uma das aberrações pedagógicas [...]" (apud Nosella, 1992, p. 18).

Por fim, entende-se ser necessário enfrentar a complexa questão da formação de jovens trabalhadores, associados na produção da vida. Para tanto, deve-se retomar o acúmulo da produção teórica e política, sobre as relações entre trabalho, cultura e educação, no espaço da escola e no próprio espaço do trabalho. Além disso, acredita-se que essa abordagem é determinante, na interface com as reflexões e desafios, postos pela temática, singular, da juventude trabalhadora brasileira. Estar atento a como os jovens fazem, pensam e sentem o trabalho associado é sempre um bom recomeço.

18 Informação obtida em entrevista coletiva, realizada com jovens da Cadeia do Skate, em novembro de 2007.

19 A relação entre a escola e a "outra economia" tem sido objeto de reflexão de diversos atores sociais, que vêm construindo ou apoiando iniciativas no campo de economia popular solidária. Ver, por exemplo: Kruppa (2005), Tiriba e Picanço (2004). No sítio da Associação Brasileira de Pesquisadores em Economia Solidária (ABPES) está publicado um levantamento da produção acadêmica sobre formação e educação em economia solidária, relativa aos anos 1990 a 2006. Informações podem ser obtidas no sítio www.abpes.com.br/?q=biblio

20 O tema da produção e legitimação de saberes no trabalho é uma das áreas de estudo em desenvolvimento, no campo TrabalhoEducação. Indica-se, para consulta, as produções de Fischer (2004, 2006) e a Revista Educação Unisinos (edição de 2006). 


\section{Referências}

Abramo, H. W. (1997). Considerações sobre a tematização da juventude no Brasil. Revista Brasileira de Educação, $5 / 6,25-36$.

Bottomore, T. (Org.). (1993). Dicionário do pensamento marxista. Rio de Janeiro: Zahar.

Branco, P. P. M. (2005). Juventude e trabalho: desafios e perspectivas para as políticas públicas. In H. W. Abramo \& P. P. M. Branco (Orgs.), Retratos da juventude brasileira: análises de uma pesquisa nacional (pp.129-174). São Paulo: Instituto de Cidadania e Fundação Perseu Abramo.

Canclini, N. G. (1997). Culturas híbridas: estratégias para entrar e sair da modernidade. São Paulo: EDUSP, 1997.

Cariola, C. (Coord.). (1992). Sobrevivir en la pobreza: en fin de una ilusión. Caracas: Cendes/Nueva Sociedad.

Carrano, P. (Dir.). (2006). Sementes da Memória: a juventude do Quilombo São José da Serra. [Documentário Mini-DV]. Niterói: Observatório Jovem do Rio de Janeiro/Programa de Pós-Graduação em Educação/Universidade Federal Fluminense.

Condé, F. \& Novaes, J. R. (2007). Heróis anônimos. Democracia Viva, 36, 58-67.

Costa, A. C. G. (2004) Educação para o empreendedorismo: uma visão histórica. In R. Novaes \& P. Vannuchi (Orgs.), Juventude e sociedade: trabalho, educação, cultura e participação (pp. 242-258). São Paulo: Perseu Abramo.

Cunha, G. C. \& Silva, A. A. (2006). A política nacional de trabalho para a juventude em sua primeira infância: notas para uma avaliação preliminar sobre o Programa Primeiro Emprego (2003-2007). Revista de Políticas Públicas e Gestão Governamental, 5 (2), 79-103.

Dayrell, J. (2003). O jovem como sujeito social. Revista Brasileira de Educação, 24, 40-52.

Dieese. (2006). A ocupação dos jovens nos mercados de trabalho metropolitanos. Estudos e Pesquisas, 3 (24).

Ferretti, C. J., Zibas, D. M. L. \& Tartuce, G. L. B. P. (2004). Protagonismo juvenil na literatura especializada e na reforma do ensino médio. Cadernos de Pesquisa, 34 (122), 411-423.

Fischer, M. C. B. (2004). Notas sobre saberes da experiência e a constituição de empreendimentos econômicos solidários. Ciências Sociais Unisinos, 40 (164), 139-151.

Fischer, M. C. B. (2006). Uma outra produção, validação e legitimação de saberes é possível... e necessária. Trabalho Ë Educação, 12 (1), 63-72.

Fischer, M. C. B. \& Tiriba, L. (2007). Jovens trabalhadores associados na produção da vida: entre o desemprego, a precarização do trabalho e a economia popular solidária. Boletim Salto para o Futuro, 1, 62 -78.

Fontes, V. (1997). Capitalismo, exclusões e inclusão forçada. Revista Tempo, 2 (3), 34-58.

Gramsci, A. (1982). Os intelectuais e a organização da cultura. Rio de Janeiro: Civilização Brasileira.

Guillerm, A. \& Bourdet, Y. (1976). Autogestão: uma mudança radical. Rio de Janeiro: Zahar.

Guimarães, N. A. (2005). Trabalho: uma categoria-chave no imaginário juvenil? In H. W. Abramo \& P. P. M. Branco (Orgs.), Retratos da juventude brasileira: análises de uma pesquisa nacional (pp. 149-174) São Paulo: Instituto de Cidadania, Perseu Abramo.

Kruppa, S. M. P. (Org.). (2005). Economia Solidária e Educação de Jovens e Adultos. Brasília: Inep.

Lima, L., Shau, N. \& Pickersgill, M. (2006). Jovens que nascem das pedras. Revista de Economia Solidária, 2 (1).

Luxemburgo, R. (1976). Reforma o revolución. In Obras escogida. Bogotá: Pluma.

Mandel, E. (1988). Controle operário, conselhos operários, autogestão. São Paulo: Centro Pastoral Vergueiro.

Montaño, C. (2002). Terceiro setor e questão social: crítica ao padrão emergente de intervenção social. São Paulo: Cortez.

Nascimento, C. A. (2005). Educação como elemento estruturante da Economia Solidária. In S. M. P. Kruppa (Org.), Economia solidária e educação de jovens e adultos (pp. 57-63). Brasília: Inep.

Nosella, P. (1992). A escola de Gramsci. Porto Alegre: Artes Médicas.

Nuñez, O. (1998). El manifiesto asociativo y autogestionário. Manágua: CIPRES. 
Pochamnn, M. (2007). Brasil precisa criar empregos de salários mais elevados. Recuperado em 22 outubro, 2007 de http://www.zedirceu.com.br/index.php.

Razeto, L. (1993). Economia de solidariedade e organização popular. In M. Gadotti \& F. Gutiérrez (Orgs.), Educação comunitária e economia popular (pp. 34-58). São Paulo: Cortez.

Revista Educação Unisinos, 10 (2).

Santos, B. de S. (1996). Hermenêutica ditrópica: pela democratização do conhecimento (Entrevista a Jurandir Malerba). Registro, 3 (5), Caderno Especial.

Santos, B. de S. (2002). Produzir para viver: os caminhos da produção não capitalista. Rio de Janeiro: Civilização Brasileira.

Secretaria Nacional da Economia Solidária/MTE (2010). O que é Economia Solidária. Recuperado em 12 fevereiro de 2010 de http://www.mte.gov.br/ecosolidaria/ecosolidaria_oque.asp.

Sposito, M. P. \& Carrano, P. C. R. (2003). Juventude e políticas públicas no Brasil. Revista Brasileira de Educação, 24, 16-39.

Tiriba, L. \& Picanço, I. (Orgs.). (2004). Trabalho e educação: arquitetos, abelhas e outros tecelões da economia popular solidária. São Paulo: Ideias \& Letras.

Tiriba, L. (1997). Los trabajadores, el capitalismo y la propiedad colectiva como estrategia de supervivencia y de trabajo. Contexto e Educação, Universidade de Ijuí, 11 (46).

Tiriba, L. (2001). Economia popular e cultura do trabalho: pedagogias da produção associada. Ijuí:Unijuí.

Tiriba, L. (2004). Ciência econômica e saber popular: reivindicar o popular na economia e na educação. In L. Tiriba \& I. Picanço (Orgs.), Trabalho e educação: arquitetos, abelhas e outros tecelões da economia popular solidária (pp. 75-101). São Paulo: Ideias \& Letras.

Tiriba, L. (2008). Cultura do trabalho, autogestão e formação de trabalhadores associados na produção: questões de pesquisa. Perspectiva, 26 (1).

Tommasi, L., Nogueira, M. J. \& Corrachano, M. C. (2007). Almanaque da Juventude e o Mundo do Trabalho. São Paulo: Ação Educativa, Fundação Friedrich Ebert e Projeto Redes e Juventudes.

Villasante, T. R. (1994). Los retos del asociativismo. Documentacón Social, 94, 9-21.

Wikipédia (2008). Tripalium. Recuperado em 01 agosto de 2008 de http://pt.wikipedia.org/wiki/Tripalium.

\section{Endereço para correspondência}

liatiriba@gmail.com, clarafis@cpovo.net

Recebido em: 13/05/2009

Revisado em: 23/03/2010

Aprovado em: 24/03/2010 